\title{
Role of non-transferrin bound iron in iron overload and liver dysfunction in long term survivors of acute leukaemia and bone marrow transplantation
}

\author{
P Harrison, J R Neilson, S S Marwah, L Madden, D Bareford, D W Milligan
}

\begin{abstract}
Aims-To determine whether nontransferrin bound iron is present in the serum of long term survivors of acute leukaemia and bone marrow transplantation who have liver dysfunction as indicated by consistently raised serum aspartate aminotransferase (AST) activities.

Methods-Thirty eight patients, who were at least three years from the end of treatment, were studied. Serum samples were analysed for hepatitis $\mathbf{C}$, hepatitis $B$, AST, ferritin, and non-transferrin bound iron. A bleomycin based assay was used to detect non-transferrin bound iron. $\mathrm{Pa}$ tient and blood bank records were examined to determine the number of units of transfused blood received by each patient. Results-Ten patients had consistently raised serum AST activities. Of these, two had evidence of hepatitis $C$ infection, one had chronic hepatitis $B$ infection and one had chronic graft versus host disease affecting the liver. None of these four patients had detectable non-transferrin bound iron. The remaining six patients had no obvious reason for raised AST activities, but four had non-transferrin bound iron detectable in their serum as compared with only two out of 28 patients with normal AST activities. Patients with abnormal AST activities had higher serum ferritin concentrations than those with normal AST, though serum ferritin was raised in 21 of 28 patients without liver dysfunction.

Conclusion-Non-transferrin bound iron may be found in this group of patients, suggesting that iron overload is the cause of the observed liver dysfunction. Nontransferrin bound iron may also be a more specific indicator of iron overload than the serum ferritin concentrations.

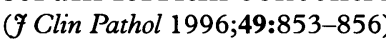

Keywords: liver dysfunction, non-transferrin bound iron, acute leukaemia, bone marrow transplantation.

Liver dysfunction is a recognised finding following treatment of haematological malignancy and has a variety of possible causes including: hepatitis B virus (HBV), ${ }^{1}$ hepatitis C $(\mathrm{HCV}){ }^{2}$ graft versus host disease (GvHD), ${ }^{3}$ and veno-occlusive disease (VOD). ${ }^{4}$ The latter is generally only seen soon after transplantation; however, the others can be responsible for continuing liver damage years after the cessation of treatment. In addition, many chemotherapeutic agents used in the treatment of haematological malignancies are known to be hepatotoxic. ${ }^{5}$

Recently, it has been suggested that iron overload is responsible for abnormal liver blood tests in some patients surviving at least one year after bone marrow transplantation (BMT). ${ }^{6}$ It is possible that this may also be the case in patients who have received chemotherapy alone for haematological malignancy.

It is known that in situations of iron overload serum iron binding capacity becomes fully saturated and that non-transferrin bound iron complexes appear in the serum. Nontransferrin bound iron is also described as free iron. Serum ferritin is increased in this situation, but ferritin functions as an intracellular iron storage protein. Only trace amounts of ferritin are present in the serum and this is glycosylated and contains little or no iron; it does not seem to function as an iron scavenger. $^{78}$ Free iron or non-transferrin bound iron has been reported in several conditions including idiopathic haemachromatosis ${ }^{9}$ and following cytotoxic chemotherapy. ${ }^{10}$ Nontransferrin bound iron may mediate tissue damage by the formation of highly reactive hydroxyl radicals from superoxide and hydrogen peroxide. ${ }^{11}$

The presence of non-transferrin bound iron can be detected using a bleomycin based assay. ${ }^{12}$ Iron is required to bind to bleomycin in the presence of ascorbate before it can cleave DNA at G-C $\left(5^{\prime} \rightarrow 3^{\prime}\right)$ and G-T $\left(5^{\prime} \rightarrow 3^{\prime}\right)$ sequences. If bleomycin, ascorbate and DNA are in excess, the amount of DNA degradation is proportional to the concentration of nontransferrin bound iron. ${ }^{12}$

In cases where iron overload is the cause of abnormal liver blood tests following treatment of haematological malignancy, we postulate that serum non-transferrin bound iron should be present. Additionally, in a population of multitransfused patients non-transferrin bound iron should be a better indicator of iron mediated liver dysfunction than serum ferritin. In such a population increased ferritin concentrations may be found in many subjects without liver dysfunction. Liver dysfunction can also result in an increase in serum ferritin concentrations. ${ }^{13}$ 
Table 1 Details of patient diagnosis and treatment

\begin{tabular}{|c|c|c|c|c|}
\hline \multirow[t]{2}{*}{ Diagnosis } & \multirow[t]{2}{*}{ Total } & \multicolumn{3}{|l|}{ Treatment } \\
\hline & & Chemotherapy & Autologous BMT & Allogeneic BMT \\
\hline AML & 18 & 12 & 6 & - \\
\hline ALL & 7 & 3 & 4 & - \\
\hline CML & 2 & - & - & 2 \\
\hline Hodgkin's disease & 6 & - & 6 & - \\
\hline $\begin{array}{l}\text { Non-Hodgkin's } \\
\text { lymphoma }\end{array}$ & 4 & - & 4 & - \\
\hline Plasmacytoma & 1 & - & 1 & - \\
\hline
\end{tabular}

$\mathrm{AML}=$ acute myeloid leukaemia $\mathrm{ALL}=$ acute lymphoblastic leukaemia $\mathrm{CML}=$ chronic myeloid leukaemia.

Table 2 Median (95\% confidence interval) AST activities (units/l) in patients with and without non-transferrin bound iron

\begin{tabular}{lll}
\hline & Number of patients & Median AST activities \\
\hline Non-transferrin bound iron & 6 & $47.5(25.7-69.3)^{\star}$ \\
No non-transferrin bound iron & 28 & $23.0(14.7-31.3)$ \\
\hline
\end{tabular}

${ }^{\star} \mathrm{p}=0.017$.

\section{Methods}

All surviving patients treated within a single unit for acute leukaemia or who underwent BMT (autologous or allogeneic), and who were at least three years from the end of treatment, were identified and studied. Serum samples were assayed for aspartate aminotransferase (AST) activity. Ferritin was assayed by microparticle enzyme immunoassay (Abbott Diagnostics).

All samples were screened for $\mathrm{HCV}$ infection by a third generation enzyme linked immunosorbant assay (ELISA) (Ortho Diagnostics). Positive results in the screening ELISA were were confirmed using a second EIA (Murex Diagnostics) and a recombinant immunoblot assay (Ortho Diagnostics). All samples were also assessed for HCV RNA by a reverse transcription polymerase chain reaction (RT-PCR) assay as described by Garson $e t$ al. ${ }^{14}$ Screening for HBV was performed by EIA (Organon Teknika) for HBV surface antigen and by enhanced luminescent immunoassay (Johnson and Johnson) for HBV core antigen.

Assays for non-transferrin bound iron were performed blind in a different institution (City

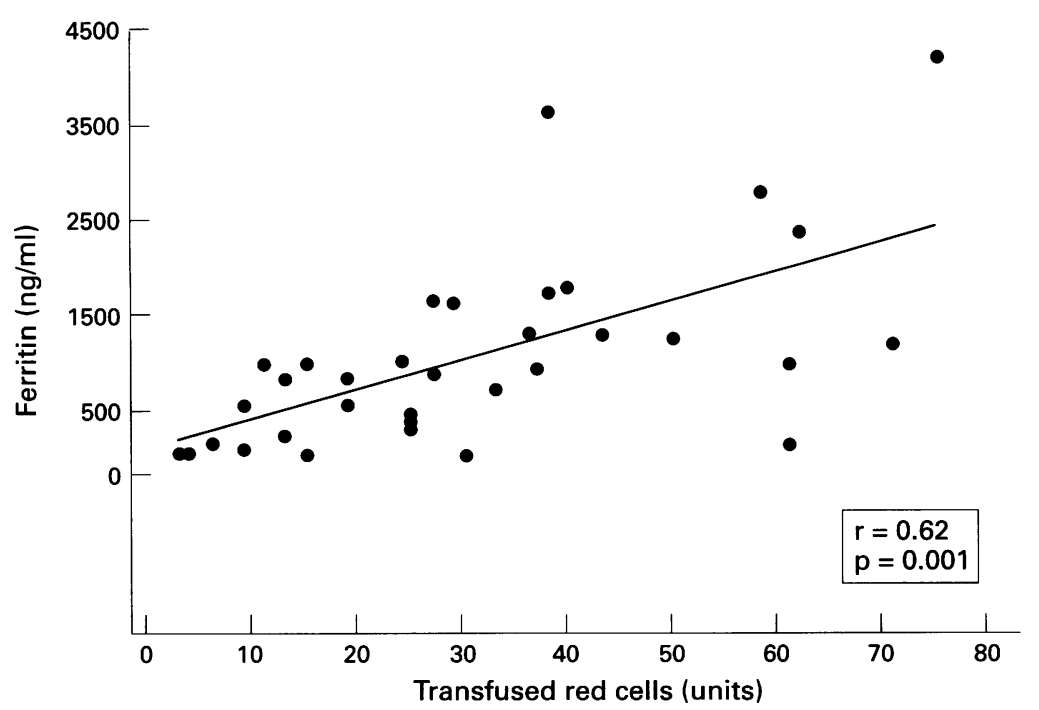

Figure 1 Correlation between serum ferritin concentrations and number of red cell transfusions.
Hospital, Birmingham). The bleomycin assay used to measure non-transferrin bound iron has been described elsewhere ${ }^{10}$ Briefly, $0.4 \mathrm{ml}$ of DNA at $1 \mathrm{mg} / \mathrm{ml}$ (Sigma, Poole, Dorset, UK), $50 \mu \mathrm{l}$ bleomycin $0.6 \mathrm{mM}$ (Lundbeck), $0.1 \mathrm{ml}$ magnesium chloride $50 \mathrm{mM}(\mathrm{BDH}$, Poole, Dorset, UK), $0.1 \mathrm{ml}$ Tris buffer, $\mathrm{pH} 7.4$ $(\mathrm{BDH}), 50 \mu \mathrm{l}$ ascorbate $7.5 \mathrm{mM}(\mathrm{BDH})$, and $20 \mu \mathrm{l}$ of sample or control were incubated in clean plastic test tubes for 30 minutes at $37^{\circ} \mathrm{C}$. Then, $0.1 \mathrm{ml}$ EDTA $0.1 \mathrm{M}$ (BDH), $0.5 \mathrm{ml}$ thiobarbituric acid $1 \% \mathrm{w} / \mathrm{v}$ in $50 \mathrm{mM}$ sodium hydroxide (Sigma), and $0.5 \mathrm{ml}$ hydrochloric acid $25 \% \mathrm{w} / \mathrm{v}$ in distilled water $(\mathrm{BDH})$ were added and the mixture heated for five minutes at $100^{\circ} \mathrm{C}$ to develop TBA (thiobarbituric acid) reactivity. After cooling, the absorbance was measured at $532 \mathrm{~nm}$ using a PU 8610 kinetics spectrophotometer (Pye Unicam) and compared with the appropriate standards and blanks. The bleomycin assay used to measure serum non-transferrin bound iron does not measure iron bound to transferrin or ferritin. ${ }^{12} 15$

Individual medical and blood bank records were examined to determine the number of units of blood transfused during treatment and to record all elevated AST activities. For the purposes of this study an AST activity was considered consistently raised if it was $>35 \mathrm{U} / 1$ on two samples at least six months apart (upper end of normal range $30 \mathrm{U} / \mathrm{l}$ ).

Statistical analysis was performed using the Minitab for Windows release 10 statistics package. The Mann-Whitney test and the Pearson correlation test were used.

\section{Results}

A total of 38 patients was studied. Table 1 shows details of patient diagnosis and treatment.

Ten patients were found to have consistently 용 raised AST activities and four of these had a clear cause: two had evidence of $\mathrm{HCV} \stackrel{3}{3}$ infection, being positive by both the EIAs, RIBA and RT-PCR; one had chronic HBV infection and chronic active hepatitis on liver $\stackrel{9}{9}$ biopsy; and a further patient had biopsy confirmed chronic GvHD affecting the liver. Tests for HBV and HCV were negative in all $N_{\infty}$ other patients. None of the four patients with a $N$ clear cause for an increased AST activity had detectable non-transferrin bound iron in their serum, and they have been excluded from the following statistical analysis. Six patients had raised AST activities without an obvious $\stackrel{\infty}{\oplus}$ explanation. Four of these had detectable nontransferrin bound iron in their serum com- $\vec{\partial}$ pared with only two of 28 patients with normal $\stackrel{\circ}{\circ}$ AST activities $(p=0.0003)$. Table 2 shows $\mathbb{Q}$ AST activities found in patients with and without non-transferrin bound iron in their serum. Table 3 shows characteristics of patients found 8 to have serum non-transferrin bound iron.

In all six patients with no obvious cause for their raised AST activities the ferritin concentration was greatly raised (range 980-4214 $\mathrm{ng} / \mathrm{ml}$; normal ranges: men $30-233 \mathrm{ng} / \mathrm{ml}$, women $6-81 \mathrm{ng} / \mathrm{ml}$ ). Although these ferritin concentrations were significantly higher than 
Table 3 Characteristics of patients found to have serum non-transferrin bound iron (patients 1-4 have consistently raised AST activities)

\begin{tabular}{llllllll}
\hline $\begin{array}{l}\text { Patient } \\
\text { number }\end{array}$ & Diagnosis & Age (years) & Sex & $\begin{array}{l}\text { Years from } \\
\text { diagnosis }\end{array}$ & $\begin{array}{l}\text { Number of red cell } \\
\text { units transfused }\end{array}$ & $\begin{array}{l}\text { Non-transferrin bound } \\
\text { iron concentration } \\
(\mu m o l / l)\end{array}$ & $\begin{array}{l}\text { Serum ferritin } \\
\text { concentration } \\
(n g / m l)\end{array}$ \\
\hline 1 & AML & 58 & F & 10.8 & 75 & 0.8 & 4214 \\
2 & AML & 33 & F & 3.0 & 38 & 0.7 & 1740 \\
3 & AML & 68 & M & 3.0 & 38 & 0.5 & 3644 \\
4 & ALL & 19 & F & 3.6 & 61 & 0.5 & 9.4 \\
5 & ALL & 23 & F & 7.2 & 15 & 0.2 & 1020 \\
6 & AML & 61 & M & 10.5 & 24 & & \\
\hline
\end{tabular}

$\mathrm{AML}=$ acute myeloid leukaemia; $\mathrm{ALL}=$ acute lymphoblastic leukaemia.

those seen in patients with normal AST activities ( $p=0.0055), 21$ of the 28 patients with normal AST activities also had a raised serum ferritin concentration (range 103-2815 ng/ml). We found no correlation between ferritin and the presence of non-transferrin bound iron. However, all patients with raised AST and non-transferrin bound iron had ferritin concentrations of over $1000 \mathrm{ng} / \mathrm{ml}$ compared with nine of the 28 patients with normal AST activities. There was a moderate correlation between ferritin concentrations and the number of units of blood transfused (fig 1).

Those patients with raised AST activities received a median of 49 units of blood (range 11-75) compared with a median of 25 (range 4-71) in those with normal AST activities ( $\mathrm{p}=$ 0.037). The four patients with both nontransferrin bound iron and raised AST had received an median of 50 units $(38,38,61,75)$.

\section{Discussion}

It is well known that intensive treatment for haematological malignancy can have significant long term adverse effects. Well described examples include cardiomyopathy due to anthracyclines ${ }^{16}$ lung fibrosis due to bleomycin, ${ }^{17}$ cataracts following total body irradiation, ${ }^{18}$ and endocrine dysfunction, including growth retardation, in children. ${ }^{19}$ Liver damage is also a recognised finding and, as already discussed, has several well described causes. Drugs, especially cytotoxic agents, may cause abnormal liver function by a variety of mechanisms and this has been reviewed extensively. ${ }^{5}$ Chronic viral hepatitis is also a well recognised complication and has been investigated extensively.

In 1988 Hetherington and Buchanan ${ }^{20}$ noted a correlation between raised serum aminotransferase values and number of prior blood transfusions in 59 children with acute lymphoblastic leukaemia. They proposed non-A non-B hepatitis as the likely cause rather than, or in addition to, chemotherapy induced hepatic injury. Iron overload was not considered as an explanation for the observed raised aminotransferase activities.

Since the identification of $\mathrm{HCV}$ as the cause of transfusion related non-A non-B hepatitis, its impact in patients treated for haematological malignancy has been explored in several centres. In one study a group of 50 Italian children with leukaemia (in long term remission) and chronic liver disease was examined. ${ }^{21}$ Twenty three $(46 \%)$ of the children were found to be $\mathrm{HCV}$ antibody positive. However, this figure may be an underestimate as a result of the use of a first generation EIA which may have given false negative results. Iron overload was not considered as a possible cause for the chronic liver disease in the remaining 27 (54\%) patients. In a more recent Italian study ${ }^{2}$ investigating the prevalence of $\mathrm{HCV}$ infection in patients receiving treatment for acute lymphoblastic leukaemia, 21 of 102 children had raised aminotransferase activities. Of these, 16 had evidence of $\mathrm{HCV}$ infection (using a RIBA III and RT-PCR) and five did not; again iron overload was not regarded as a possible explanation for the raised aminotransferases in those without $\mathrm{HCV}$ infection. In our study the rate of HCV infection was low (5\%) and reflects the low prevalence in the local donor population (0.028\% in 1991; unpublished data) as compared with other areas-for example, $1.3 \%$ in Italy $^{22}$ and $0.11 \%$ in Finland. ${ }^{23}$

Iron overload is a well recognised cause of liver damage. Indeed, hepatic dysfunction is one of the most frequent findings in idiopathic haemachromatosis. Iron overload due to both haemachromatosis and multiple blood transfusion results in the saturation of transferrin and the appearance of non-transferrin bound iron in the serum. ${ }^{24}$ Non-transferrin bound iron is toxic to living systems because it can act as a catalyst in the formation of highly reactive hydroxyl radicals, which in turn stimulate lipid peroxidation in membranes. ${ }^{24}$ Iron bound to ferritin and transferrin is not reactive in this way. ${ }^{25}$ It has been shown previously that in patients with leukaemia non-transferrin bound iron is only detected when transferrin is fully saturated, and that there is no significant association between serum ferritin and the presence of non-transferrin bound iron. ${ }^{10}$

Finding non-transferrin bound iron in four out of six patients with an unexplained increase in AST activity leads us to suggest that not only is iron overload responsible for the liver dysfunction, but that non-transferrin bound iron is a more specific indicator of this than serum ferritin. The latter was raised in most of our patients following treatment for haematological malignancy, whilst only $16 \%$ had unexplained increases in AST. The presence of non-transferrin bound iron in patient 5 (table 3 ) is difficult to explain, but may be a false positive result due to contamination. This patient, with a normal serum ferritin concentration, received relatively few red cell transfusions and has never had a raised AST activity.

Our findings support those of McKay et al, ${ }^{6}$ that iron overload has a causal role in liver dys- 
function following BMT. We have also shown that this may apply to patients treated with standard chemotherapy for acute leukaemia. We also agree with McKay et $a l^{6}$ that the role of venesection in these patients needs assessing, and that iron overload should be considered in any patient with persistently abnormal liver blood tests following treatment for haematological malignancy. We are currently assessing the role of venesection in such patients. In a population of patients with raised ferritin concentrations, the bleomycin assay for nontransferrin bound iron may offer a relatively simple method of identifying patients with iron induced liver damage.

1 Armitage JO, Burns CP, Kent TH. Liver disease complicating the management of acute leukaemia during remission. Cancer 1978;41:737-42

2 Aricò M, Maggiore G, Silini S, Bono F, Viganò C, Cerino A, et al. Hepatitis $\mathrm{C}$ infection in children treated for acute lymphoblastic leukaemia. Blood 1994;84:2919-22.

3 Binakoff SJ, Deeg HJ, Ferrara J, Atkinson K (eds). Graft-versus-host disease. New York: Dekker, 1990.

4 McDonald GB, Sharma P, Matheus DE, Schilman HM Thomas ED. The clinical course of 53 patients with venoocclusive disease after marrow transplantation. Trans plantation 1985;44:39:603-7.

5 Perry MC. Chemotheraputic agents and hepatotoxicity. Semin Oncol 1992;19:551-65.

6 McKay PJ, Murphy JA, Cameron S, Burnett AK, Campbell $\mathrm{P}$, Tansey $\mathrm{P}$, et al. Iron overload and liver dysfunction after allogeneic or autologous bone marrow transplantation. Bone Marrow Transplant 1996;17:63-6.

7 Worwood M, Cragg SJ, Jacobs A, McLaren C, Ricketts C, Economidou J. Binding of serum ferritin to concanavalin A Economidou J. Binding of serum ferritin to concanavalin A in patients with homozygous thalassaemia and tra
sional iron overload. Br f Haematol 1980;46:409-16.

sional iron overload. $B r \mathcal{F}$ Haematol 1980;46:409-16.
8 Worwood M, Dawkins S, Wagstaff M, Jacobs A. The purification and properties of ferritin from human serum. Biochem f 1976;157:97-103.

9 Bately RG, Lai Chung Fong P, Shamir S, Sherlock S. A non transferrin bound serum iron in idiopathic haemachromatosis. Dig Dis Sci 1980;25:340-6.
10 Harrison P, Marwah SS, Hughes RT, Bareford D Non-transferrin bound iron and neutropenia after cytotoxic chemotherapy. $\mathcal{F}$ Clin Pathol 1994;47:350-2.

11 Halliwell B, Aruoma OI, Mufti G, Bomford A. Bleomycindetectable iron in the serum from leukaemic patients before and after chemotherapy. FEBS Lett 1988;241:202-4.

12 Gutteridge JMC, Hou Y. Iron complexes and their reactivity in the bleomycin assay for radical promoting loosly bound iron. Free Radic Res 1986;2:143-51.

13 Prieto J, Barry $M$, Sherlock S. Serum ferritin in patients with iron overload and with acute and chronic liver disease. Gastroenterology 1975;68:525-33.

14 Garson JA, Tuke PW, Makris M, Briggs M, Machin SJ, Preston FE, et al. Demonstration of viraemia patterns in haemophiliacs treated with hepatitis $C$ virus contaminated factor VIII concentrates. Lancet 1990;336:1022-5.

15 Gutteridge JMC, Rowley DA, Halliwell B. Superoxide dependant formation of hydroxyl radicals in the presence of iron salts. Biochem $₹$ 1981;199:263-5.

16 Von Hoff DD, Rozencweig M, Layard M, Slavic M, Muggia FM. Daunomycin-induced cardiotoxicity in children and adults: A review of 110 cases. Am F Med 1977;62:200-8.

17 Blum RH, Carter SK, Agre K. A clinical review of bleomycin - a new antineoplastic agent. Cancer 1973;31: 903-14.

18 Livesey SJ, Holmes JA, Whittaker JA Ocular complications of bone marrow transplantation. Eye 1989;3:271-6.

19 Kirk JA, Raghupathy P, Stevens MM, Towell CT, Menser MA, Bergin M, et al. Growth failure and growth hormone deficiency after treatment for acute lymphoblastic leukaemia. Lancet 1987;i:190-3.

20 Hetherington MJ, Buchanan GR. Elevated transaminase values during therapy for acute lymphoblastic leukaemia correlate with prior blood transfusions. Cancer 1988;62: 1614-18.

21 Locascuilli A, Gornati G, Tagger A, Ribero ML, Cavalletto $\mathrm{D}$, Cavalletto $\mathrm{L}$, et al. Hepatitis $\mathrm{C}$ virus infection and chronic liver disease in children with leukaemia in long term remission. Blood 1991;78:1619-22.

22 Ferri C, Caracciolo F, Zignego AL, La Civita L, Monti M, Longombardo $\mathrm{G}$, et al. Hepatitis $\mathrm{C}$ virus infection in patients with non-Hodgkin's lymphoma. $\mathrm{Br} \mathcal{F}$ Haematol 1994;88:392-4.

23 Kohlo E, Oksanen K, Honkanen E, Naukkarinen R, Krusius $\mathrm{T}$. Hepatitis $\mathrm{C}$ antibodies in dialysis patients and patients with leukaemia. $\mathcal{F}$ Med Virol 1993;40:318-21.

24 Gutteridge JMC, Rowley DA, Griffiths E, Halliwell B. Low molecular weight iron complexes and oxygen radical reactions in idiopathic haemochromatosis. Clin Sci 1985;68:463-7.

25 Halliwell B. Superoxide-dependant formation of hydroxyl radicals in the presence of iron chelates. FEBS Lett 1978;92:321-6. 